\title{
Evaluation of Blood Pressure in Children with Hydronephrosis in Comparison with Healthy Children
}

\author{
Parsa Yousefichaijan, ${ }^{1}$ Yazdan Ghandi, ${ }^{1}$ Masomeh Alavi, ${ }^{2}$ Mohammad Rafiei, ${ }^{3}$ Ali Khosrobeigi, ${ }^{2,}$ Ali \\ Arjmand, ${ }^{1}$ and Fakhreddin Shariatmadari ${ }^{1}$ \\ ${ }^{1}$ Department of Pediatric, School of Medicine, Amirkabir Hospital, Arak University of Medical Sciences, Arak, IR Iran \\ ${ }^{2}$ Students Research Committee, Arak University of Medical Sciences, Arak, IR Iran \\ ${ }^{3}$ School of Medicine, Arak University of Medical Sciences, Arak, IR Iran \\ "Corresponding author: Ali Khosrobeigi, Students Research Committee, Arak University of Medical Sciences, Arak, IR Iran. E-mail: ali.khosrobeigi@yahoo.com
}

Received 2018 March 30; Accepted 2018 May 07.

\begin{abstract}
Background: Nowadays hypertension (HTN) is a common finding in children. Also, hydronephrosis is a common clinical condition that is referred to physicians. Kidney disease is the most common reason of secondary HTN in children.

Objectives: In this study, the researchers aimed at evaluating the relationship between HTN and hydronephrosis in children. Methods: This was a case-control study that was done on children older than four years old. The case group included children with hydronephrosis that referred to the pediatrics clinic of Amirkabir hospital in Arak, Iran. At the same time, healthy children with the same demographic condition were entered in the control group.

Results: This study was done on 328 children in case (108 children: 42 males and 66 females) and control (220 children: 98 males and 122 females) groups. The mean age of these children was $7.52 \pm 2.48$ years old. Overall, $95.4 \%$ of the case group and $85 \%$ of the control were in the normal range of diastolic blood pressure (P-value $=0.013$ ) and $99.1 \%$ of the case group and $89.5 \%$ of the control group were in the normal range for systolic blood pressure (P-value $=0.007)$.

Conclusions: It could be concluded that hydronephrosis and HTN had a relationship.
\end{abstract}

Keywords: Child, Hypertension, Hydronephrosis

\section{Background}

Obstruction lesion in the urinary tract could occur in any section of the meatus to infundibulum of the calyx. Most causes of this obstruction are congenital (1). Obstruction in the urinary tract may be identified by ultrasonography during pregnancy (2). Systolic and diastolic blood pressure usually increase from the one to eighteen years old. Hypertension in children is defined as blood pressure being greater than 95th percentile considering age, gender, and height (3). Kidney disease is the most common reason for secondary HTN in children $(4,5)$. Blood pressure of less than the 90th percentile is normal and blood pressure between 90th and 95th is pre-HTN (6).

Because HTN can cause major organ damage and early diagnosis can prevent this damage, in this study, the researchers compared blood pressure in healthy children and children with hydronephrosis.

\section{Methods}

This was a case control study that was done on children older than four years old. The case group included children with hydronephrosis that referred to the pediatrics clinic of Amirkabir hospital in Arak, Iran. At the same time, healthy children without any problem in their kidney and urinary system and with the same demographic condition (age, gender, socioeconomic status, etc.) entered the control group.

Blood pressure and height of children were measured. For measuring the blood pressure, standard methods and citizen digital blood pressure monitor were used (REFCH311B).

\section{Results}

In this study, 108 children with hydronephrosis entered the case group and 220 healthy children entered the control group. The mean age of these children was $7.52 \pm$ 


\begin{tabular}{|c|c|c|c|}
\hline Group & Mean & Standard Deviation & P-Value \\
\hline Case & 7.28 & 2.43 & \multirow{3}{*}{0.233} \\
\hline Control & 7.63 & 2.51 & \\
\hline Total & 7.52 & 2.48 & \\
\hline \multicolumn{4}{|c|}{ Table 2. Children's Gender } \\
\hline \multirow{2}{*}{ Group } & \multicolumn{2}{|c|}{ Gender, No. (\%) } & \multirow{2}{*}{ P-Value } \\
\hline & Male & Female & \\
\hline Case & $42(38.9)$ & $66(61.1)$ & \multirow{3}{*}{0.330} \\
\hline Control & $98(44.5)$ & $122(55.5)$ & \\
\hline Total & $140(42.7)$ & $188(57.3)$ & \\
\hline \multicolumn{4}{|c|}{ Table 3. Children's Weight } \\
\hline Group & Mean & Standard Deviation & P-Value \\
\hline Case & 25.47 & 10.65 & \multirow{3}{*}{0.244} \\
\hline Control & 26.95 & 10.94 & \\
\hline Total & 26.46 & 10.85 & \\
\hline \multicolumn{4}{|c|}{ Table 4. Children's Height } \\
\hline Group & Mean & Standard Deviation & P-Value \\
\hline Case & 122.51 & 10.65 & \multirow{3}{*}{0.178} \\
\hline Control & 125.12 & 16.78 & \\
\hline Total & 124.27 & 16.49 & \\
\hline
\end{tabular}

2.48 years old (Table 1$)$. In this study, 140 children (42.7\%) were male and 188 (57.3\%) were female (Table 2). The mean weight of these children was $26.46 \pm 10.85 \mathrm{~kg}$ (Table 3). The mean height of these children was $124.27 \pm 16.49 \mathrm{~cm}$ (Table 4).

This study showed that 10 children of the control group (4.5\%) had diastolic HTN, blood pressure of 23 children in the control group (10.5\%) was in the pre-HTN range, and blood pressure of five children in the case group (4.6\%) was in the pre-HTN range (Table 5).

Also, this study showed that 12 children of the control group (5.5\%) had diastolic HTN, blood pressure of 11 chil-

\begin{tabular}{lcccc}
\hline Table 5. Diastolic Blood Pressure in Children & \multirow{2}{*}{ P-Value } \\
\hline \multirow{2}{*}{ Group } & \multicolumn{3}{c}{ Diastolic BP, No (\%) } \\
\cline { 2 - 4 } & Normal & Pre HTN & HTN & \\
\hline Case & $103(95.4)$ & $5(4.6)$ & $0(0)$ & \multirow{2}{*}{0.013} \\
Control & $187(85.0)$ & $23(10.5)$ & $10(4.5)$ & \\
\cline { 1 - 2 } Total & $290(88.4)$ & $28(8.5)$ & $10(3.0)$ & \\
\hline
\end{tabular}

\begin{tabular}{lcccc}
\hline Table 6. Systolic Blood Pressure in Children & \multicolumn{3}{c}{ P.Value } \\
\hline \multirow{2}{*}{ Group } & \multicolumn{3}{c}{ Systolic BP, No (\%) } & \\
\cline { 2 - 4 } & Normal & Pre HTN & HTN & \\
\hline Case & $107(99.1)$ & $1(0.9)$ & $0(0)$ & \\
\cline { 1 - 3 } Control & $197(89.5)$ & $11(5.0)$ & $12(5.5)$ & 0.007 \\
\cline { 1 - 2 } Total & $304(92.7)$ & $12(3.7)$ & $12(3.7)$ & \\
\hline
\end{tabular}

dren in the control group (5.0\%) was in the pre-HTN range, and one child in the case group (0.9\%) had blood pressure in the pre-HTN range (Table 6).

\section{Discussion}

Although prevalence of chronic kidney disease in children is less than adults, in these children the prevalence of HTN is 10 times more than healthy children (7). Furthermore, HTN and CKD have a relationship with each other. The function of the kidneys is basic for keeping fixed the blood pressure. Therefore, with a decrease of kidney function, blood pressure will increase $(8,9)$.

In this study, the researchers compared blood pressure in children with or without hydronephrosis. The study found a relationship between children with or without hydronephrosis in systolic and diastolic blood pressure.

Ameur et al. reported that bilateral hydronephrosis could increase blood pressure and cause renal failure by inappropriate production of renin and chronic urinary retention (10).

Carlstrom et al. reported that all hydronephrotic mice had a salt-sensitive HTN and their HTN correlated with the degree of hydronephrosis (11).

Munoz et al. reported that young patients with hydronephrosis may experience an episode of acute hypertensive (12).

\subsection{Conclusion}

According to the current results, it could be concluded that hydronephrosis has a relationship with systolic and diastolic HTN and it seems that this relationship for systolic HTN is stronger than diastolic HTN. Therefore, in the treatment of hydronephrosis, systolic and diastolic HTN should be considered. Future studies on this topic are recommended.

\section{Acknowledgments}

The authors gratefully acknowledge the research council of Arak University of Medical Sciences (grant number: 1219) for their financial support. This work was performed 
in partial fulfillment of the requirements for MD of Masomeh Alavi, at the school of medicine, Arak University of Medical Sciences, Arak, Iran.

\section{References}

1. Lameire N, Van Biesen W, Vanholder R. Acute renal failure. Lancet. 2005;365(9457):417-30. doi: 10.1016/S0140-6736(05)17831-3. [PubMed: 15680458]

2. Yousefichaijan P, Dorreh F, Rafeie M, Sharafkhah M, Safi F, Amiri M, et al. Congenital anomalies of kidney and upper urinary tract in children with congenital hypothyroidism; a case-control study.J Renal Inj Prev. 2015;4(4):120-6. doi: 10.12861/jrip.2015.26. [PubMed: 26693499]. [PubMed Central: PMC4685982].

3. Pakniyat A, Yousefichaijan P, Parvizrad R, Qaribi M. Hypertension in children in emergency department. J Renal Inj Prev. 2016;5(3):1713. doi: 10.15171/jrip.2016.36. [PubMed: 27689117]. [PubMed Central: PMC5040007]

4. Gavrilovici C, Boiculese LV, Brumariu O, Dimitriu AG. [Etiology and blood pressure patterns in secondary hypertension in children]. Rev Med Chir Soc Med Nat Iasi. 2007;111(1):70-81. [PubMed: 17595849].

5. Kapur G, Ahmed M, Pan C, Mitsnefes M, Chiang M, Mattoo TK Secondary hypertension in overweight and stage 1 hypertensive children: a Midwest Pediatric Nephrology Consortium report. J Clin Hypertens (Greenwich). 2010;12(1):34-9. doi: 10.1111/j.17517176.2009.00195.x. [PubMed: 20047628].
6. Yousefichaijan P, Khosrobeigi A, Soltani M, Ghandi Y, Mojtahedi F. Evaluation of blood pressure in children with idiopathic overactive bladder syndrome. Saudi J Kidney Dis Transpl. 2018;29(3):540-4. doi: 10.4103/1319-2442.235177.

7. Olowu WA. Pre-treatment considerations in childhood hypertension due to chronic kidney disease. World J Nephrol. 2015;4(5):50010. doi: 10.5527/wjn.v4.i5.500. [PubMed: 26558187]. [PubMed Central: PMC4635370].

8. Horowitz B, Miskulin D, Zager P. Epidemiology of hypertension in CKD. Adv Chronic Kidney Dis. 2015;22(2):88-95. doi: 10.1053/j.ackd.2014.09.004. [PubMed: 25704344].

9. Gallibois CM, Jawa NA, Noone DG. Hypertension in pediatric patients with chronic kidney disease: management challenges. Int J Nephrol Renovasc Dis. 2017;10:205-13. doi: 10.2147/IJNRD.S100891. [PubMed: 28794651]. [PubMed Central: PMC5538700].

10. Ameur A, Zarzur J, Jira H, Touiti D, el Alami M, Abbar M. [Hydronephrosis arterial hypertension. Report of 4 cases]. Ann Urol (Paris). 2002;36(3):157-61. French. [PubMed: 12056086].

11. Carlstrom M, Wahlin N, Sallstrom J, Skott O, Brown R, Persson AE. Hydronephrosis causes salt-sensitive hypertension in rats. J Hypertens. 2006;24(7):1437-43. doi: 10.1097/01.hjh.0000234126.78766.00. [PubMed: 16794495].

12. Munoz AI, Baralt JF, Melendez MT. Arterial hypertension in infants with hydronephrosis. Report of six cases. Am J Dis Child.1977;131(1):3840. [PubMed: 835520]. 